\title{
RESIDENT PERCEPTIONS OF COMMUNITY WELL-BEING IN A RESOURCE TOWN
}

\author{
ISAAC GLICK \\ Co-West Associates \\ Edmonton, Alberta
}

\begin{abstract}
The traditional image of resource towns emphasizes problems and negative self-image. In an effort to redirect planning efforts away from the mitigation of negative impacts, thirty residents of Fort McMurray were interviewed to establish factors which promote or hinder community well-being. Subsequently, these factors were rated by a larger sample of residents. The findings indicate that residents value such factors as commitment, initiative and local involvement-indicating that community residents, themselves, constitute an important resource in the development of community well-being. These findings have implications for resource development communities and community services.
\end{abstract}

On the first anniversary of Three Mile Island, Ellen Goodman of the Washington Post, in reflecting on the fact that science had no solution for the technical problem, observed somewhat cynically that "What we do have is a $\$ 375,000$ Federal grant to study chronic stress." She predicted that by the second anniversary "We'll be experts in living with nuclear plant stress, but rank amateurs in getting rid of the sources,"

In Canada, for a long time, we exhibited something of the same "skill" with respect to boom towns, a reluctance to get to the heart of the matter. We have identified the characteristics of boom towns, we are experts in boomtown stress, but not very skilled "in getting rid of the sources."

In considering boomtown stress, it is sometimes implied that all that is needed is more money, more amenities, more "mitigating measures." When these have proved inadequate, the reflex response has been to "try harder," to allocate more resources.

For every problem there is a range of solu- tions: those that treat the problem; those that alleviate the problem; those that avoid; those that prevent, or, as was the case when "all the king's horses and all the king's men couldn't put Humpty together again," those that maintain the problem. Change theorists (Watzlawick, Weakland and Fisch, 1974) suggest that such an impasse calls for a change of focus, and/or intervention at a different level.

This paper reports on a study that involved such a change of focus-a study that involved the identification of the factors of community well-being as perceived by residents of Fort McMurray during the last ten months.

Social scientists know that habitual ways of seeing can sometimes also limit perception. Walter Lippman spoke of "the picture in our heads," while Boulding (1973), and Polak (1973) theorized about "the image," and Kuhn (1970), elaborated the concept of the paradigm as a shared set of assumptions by which people "see" the world. Even a disciplined way of "secing" risks becoming 
a mind set that inhibits new discovery and sometimes resists new information.

Usually new ways of seeing arise from the anomalies of conventional wisdom, when the usual explanations fail or the impossible happens.

With respect to resource towns, several anomalies can be cited: some people obviously thrive in the same circumstances from which others flee; the environment that some individuals find stimulating others find extremely stressful; in the midst of relative affluence, low unemployment, and lucrative incentives, considerable dissatisfaction, frustration, and boredom are reported. The almost exclusive preoccupation with boomtown pathologies by the media, researchers, and planners, is an anomaly in itself. If negative impacts can be identified in advance and mitigating measures planned and implemented, it should be equally possible to identify and plan for personal and community well-being requirements.

\section{THE PROBLEM}

This study undertook to have residents of a resource town identify the factors of community well-being, and to determine what fosters and what frustrates this community well-being. The study hoped to make explicit the community norm or ideal that is usually left unspecified in the language and literature of social and community impact assessments. In a broader context, what are the conditions of community well-being which an industrial society must consciousiy cultivate? In attempting to formulate a conceptual image of community well-being that could redirect planning, the study hoped to identify the facilitating conditions and necessary initiatives that would help shift the primary focus from the problems of resource towns to the community well-being potential.

\section{BACKGROUND}

Resource town literature, psychological image theory, inescapable observation, and some very simple logic provided the impetus for this inquiry.

Resource town literature has been onesided in its description of community problems. Image theory suggests that awareness of ideal values is the first step in the conscious creation of the future, (and of communities), since the image determines choiceoriented initiatives. Polak (1973) emphasized that society must give thought to practical methods of image change. If negative impacts can be anticipated, and mitigating measures implemented, it should also be possible to identify goals for personal and community well-being and to invest planning and facilitating resources there. Resident perceptions were deemed essential.

\section{THE INTERVIEWS}

The study consisted of three phases: (1) indepth interviews with a selected sample of 30 long-time residents to develop lists of factors that foster or hinder community well-being; (2) distribution of these lists to a much larger random community sample to obtain their ratings of the respective factors; and (3) a seminar in which a sample of participants was brought together to report findings and to obtain their assessment of results and of the process by which the data was obtained.

Each of the 30 interviews of round one was introduced with this statement: "Our interest is to learn from persons who have experienced life in a resource town during a boom period, what you see as most essential to achieve community health and stability, a condition we call 'community well-being.' Since this may mean different things to different people, and may even change over time for the same person, our task is to find out what are the most central or important elements of community well-being as seen by most residents."

\section{THE FINDINGS}

The round one interview data were summarized and sorted by a content analysis process into six categories fostering community 
well-being: PERSONAL ATTRIBUTES, VALUE ASSUMPTIONS, LEADERSHIP ARRANGEMENTS, COLLECTIVE ACTIONS (involving government, community, and industry), ENVIRONMENTAL FACTORS, and COMMUNITY NECESSIIIES and CONVENIENCES, Similarly, factors hindering community well-being were: PERSONAL ISSUES: LEADERSHIP ISSUES and IMPACT ISSUES.

In round two, the factors thus identified were rated on their importance in promoting and hindering community well-being.

Ironically, there was greater unanimity about factors that "help," despite the fact that more attention has traditionally been given to negative factors. It was also noted that factors typically associated with boom towns, such as the pace, stress, transience, crowding, and isolation, were rated high by fewer residents than more subjective factors. One may infer that many residents consider these matters of less relative significance than the literature and the media have implied.

For factors facilitating community wellbeing, the highest ratings by 75 per cent or more of respondents (Table 1) highlighted: PERSONAL ATTRIBUTES such as commitment, involvement, initiative, and integrity; SHARED RESPONSIBILITIES such as cOoperation, local government, and informed planning; LEADERSHIP ROLES of government and industry to FACILITATE local aspiration and responsibility; the stabilizing function of the BASIC FAMILY SERVICES at affordable costs; and ENVIRONMENT characterized by economic stability, natural and social appeal for putting down roots, and that provides reason for trust and contentment.

\section{CONCEPTUAL IMAGE}

An outline of a conceptual image of community well-being that emerges from the data is presented in Figure 1. The high ratings given to commitment, involvement, initiative, local government, and organizing locally, conveys an assumption among residents that community well-being is first of all a local responsibility, notwithstanding the supporting and participating roles of government and industry. Responses imply

\section{FIGURE 1 \\ An Emerging Image of Community Well-Being}

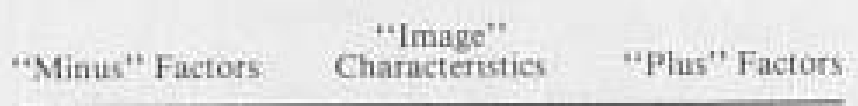

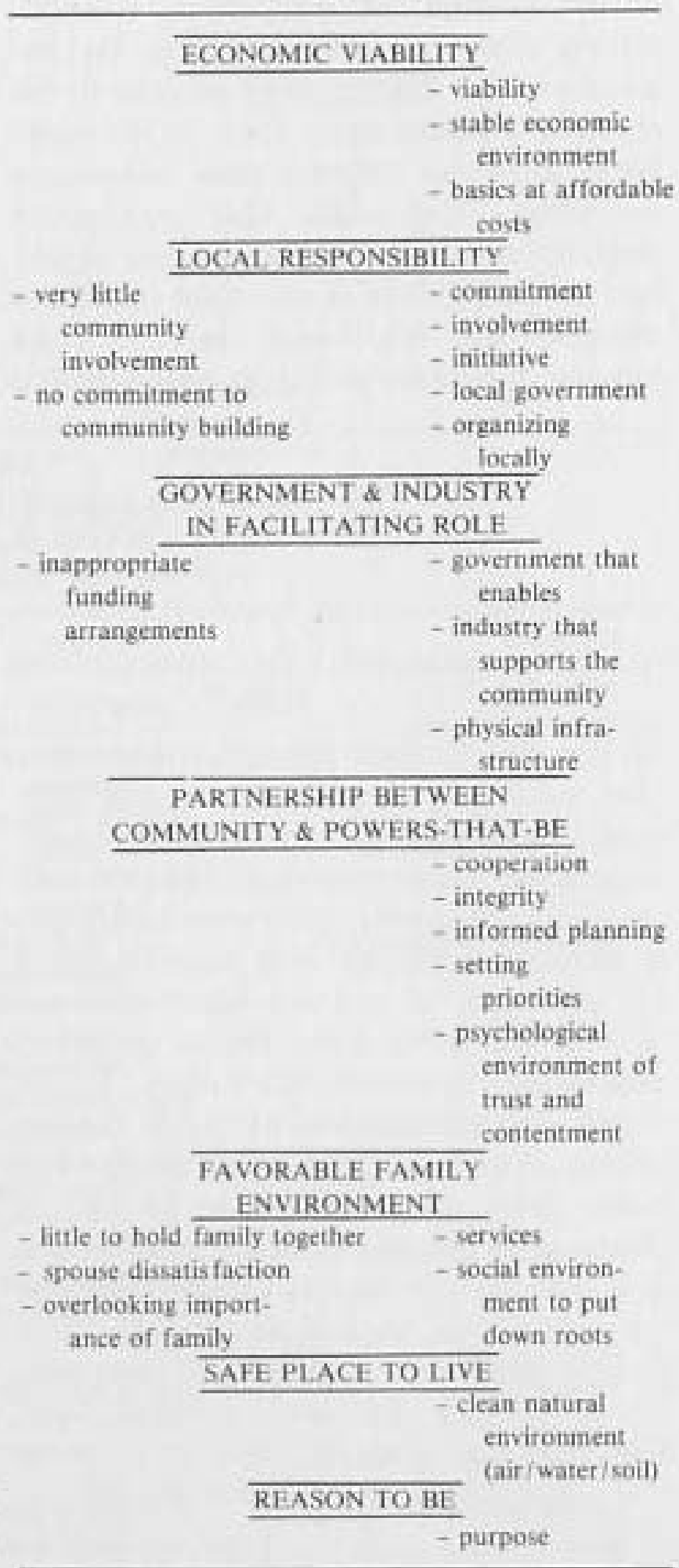


that government and industry can facilitate, but cannot provide, community well-being.

Related implications accent local input in resource town planning, local responsibility for its administration, and a style by government and industry that optimizes "opportunity" in ways that foster rather than frustrate the highly rated personal attributes indicated above.

The findings demonstrate a solutionseeking orientation among residents that contrasts with the descriptive orientation of the resource town literature. Thus, to the extent government and industry value community well-being, they will find community residents an important resource and significant partner. Failing to take these issues into account, the traditional resource town scenario too often illustrates how intended solutions can conspire to perpetuate the cycle of negative impacts.

Recognition of the essential role of stable families in a resource town emerged as both a personal and a leadership issue with far reaching implications. For town planning, it means appropriate family housing, ready access to parks and playgrounds for mothers and small children, public transportation that permits a young parent to get out of the house, while the family car is at work. For recruitment, it means meeting with both spouses (where applicable) to discuss the interests, concerns, and skills of both, even though only one is being hired. Facilitating meaningful connections in the community for the "other" spouse would foster some priority to children's needs and to home and home life, above maximizing income. For

\section{TABLE 1 \\ Factors Rated EXTREME1Y or VERY Important for, and EXTREME or MAJOR Hindrance to, Community Well-Being by $75 \%$ or More of Round Two Respondents}

\begin{tabular}{|c|c|c|c|}
\hline Cafegories & & Factors & Percentage \\
\hline $\begin{array}{l}\text { Thas "Help. . ."t: } \\
\text { Personal Aitributes }\end{array}$ & - & 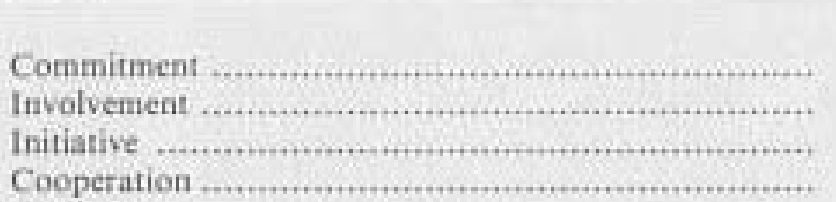 & $\begin{array}{l}90,6 \\
85.6 \\
84.7 \\
77.6\end{array}$ \\
\hline Value Assumptions & - & 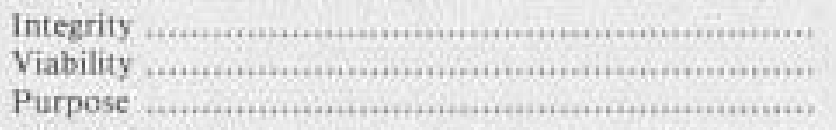 & $\begin{array}{l}85,7 \\
82,5 \\
74,7\end{array}$ \\
\hline Leaderskip Arrangements & - & 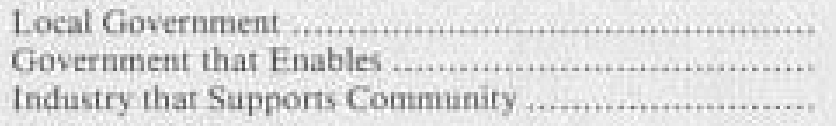 & $\begin{array}{l}86.3 \\
84,8 \\
80,4\end{array}$ \\
\hline Collective Actions & - & 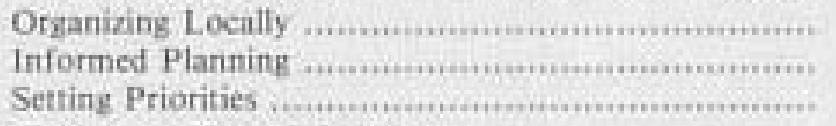 & $\begin{array}{l}78.4 \\
78.1 \\
75.8\end{array}$ \\
\hline Environmental Factors. & - & 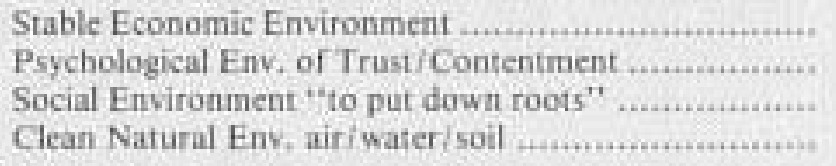 & $\begin{array}{l}85.6 \\
82.7 \\
82.5 \\
76.7\end{array}$ \\
\hline Conmunity Conveniences/Needs & - & 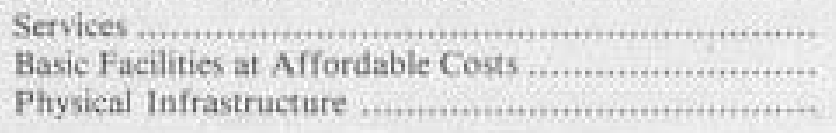 & $\begin{array}{l}90.8 \\
86.5 \\
85.6\end{array}$ \\
\hline $\begin{array}{l}\text { That }{ }^{*+} \text { Hinder ...."t: } \\
\text { Personal Issues }\end{array}$ & - & 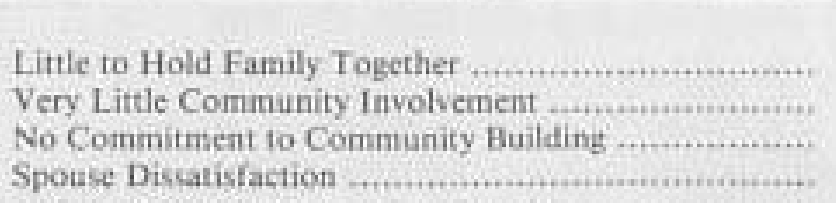 & $\begin{array}{l}87,8 \\
87,3 \\
82,8 \\
75,5\end{array}$ \\
\hline Leaderihip Issues & - & 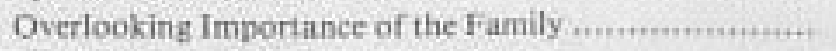 & 77,6 \\
\hline Impact Issues & - & 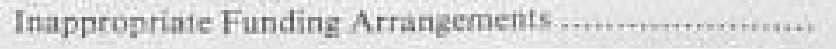 & 76.0 \\
\hline
\end{tabular}




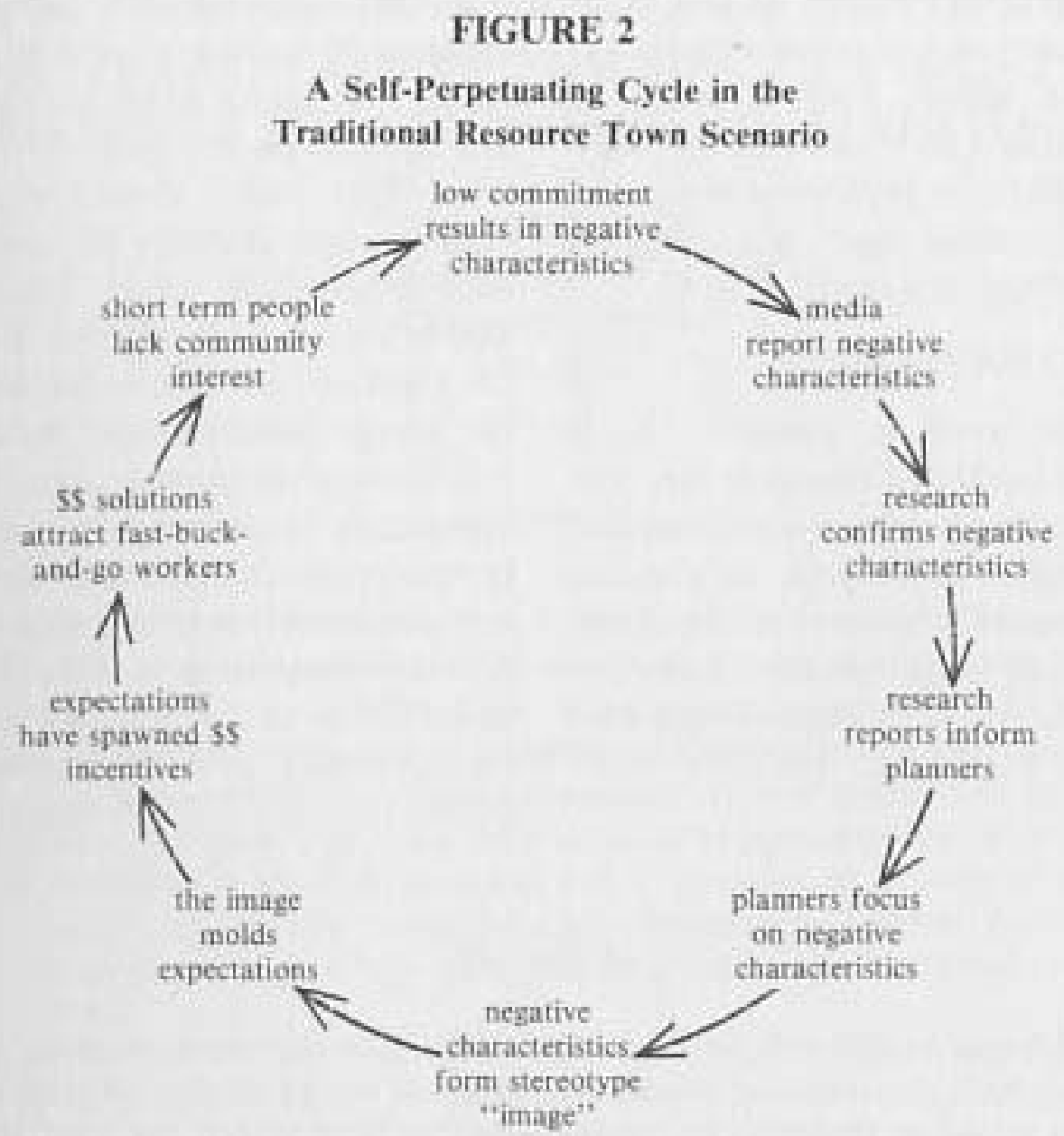

employers, it means recognizing that men/women need time to be parents and spouses, when length or number of work shifts are being planned, or it may mean providing day care, or encouraging noon breaks at home to overlap with children in cases where both parents are working. It may also mean hiring incentives that are oriented toward family and community instead of individual isolation bonuses, for example. Finally, for government it means focussing on family needs in their commitments and priorities.

\section{RESPONSIBILITY AND CHOICE}

People in boom towns often feel vulnerable, insecure, and dissatisfied in the midst of opportunity and apparent prosperity. Because many things appear to be beyond individual or local control, it is easy to feel helpless and to take a self-defeating blamethe-government position that defines circumstances as hopeless and in the process makes them so (Seligman's "learned helplessness," 1975).

But external factors represent only half the equation, perhaps the least significant half. Studies have shown that a sense of alienation, boredom, hopelessness and helplessness can characterize boom towns. Psychological theory suggests that subjective reactions to life experiences are just as important for achieving desired outcomes as the external factors, Zautra and Simons (1979) identify two sets of human needs relevant here. One is to diminish, avoid, and/or adjust to painful life events; the other, to develop and sustain life satisfaction by increasing competence, skills and mastery over the environment. Adjustment and competence are seen as independent of each other and meeting both of these needs is essential. Implicit is the presence of both objective and subjective dimensions, environmental and personal factors. 
One should not then expect to find solutions to community or individual stress in external remedies alone. Finding ways to enhance individual and community competence, not merely for problem solving, but also for goal setting and achieving, is especially important in a resource town.

\section{CONCLUSION}

The resource town is complex. It is nonetheless reasonable to conclude that just as negative impacts have been identified and mitigating measures introduced, so also can positive community alternatives be identified, planned for, taught, and facilitated, so that a way can be found to break the negative cycle of the traditional resource town scenario.
Image theory has provided some clues for breaking into the cycle at the point of "the image that molds expectations," (Figure 2) and for moving the cycle into a new trajectory. This study should encourage communities and planners to consider how the factors identified which foster community well-being can be facilitated. Two ingredients are essential: parallel to the development of the energy resource there must be a shared commitment by government, industry, and community to deliberately pursue community well-being objectives, by means of a process similar to that of this study; and, secondly, there must be a commitment to applied research in order to test and refine the understanding of factors associated with a positive community self-image.

\title{
RÉSUMÉ
}

\begin{abstract}
L'image traditionelle des villes où l'on exploite les ressources naturelles fait ressortir les problèmes et la perception négative liés à ces villes. Dans un effort en vue de réorienter les initiatives de planification dans une autre voie que celle la réduction des effets négatifs, on a interrogé trente résidents de Fort McMurray afin de déterminer les facteurs qui favorisent ou entravent le bien-etre de la collectivité. Ces facteurs ont par la suite été évalués par un échantillon plus important de la population. Les résultats indiquent que les habitants attachent de l'importance à certains facteurs comme l'engagement, l'esprit d'initiative et la participation aux activités locales-ce qui montre que les membres de la communauté eux-mêmes constituent une importante ressource pour le développement du bien-être de la communauté. Ces résultats ont une signification profonde pour les communautés où l'on exploite les ressources naturelles et pour les services communautaires.
\end{abstract}

\section{REFERENCES}

Boulding, $K$. The image, Ann Arbor, U, of Michigan Press, 1973.

Glick, L. Boom towns: a quest for well-being. Edmonton: Canadian Mental Health Association, 1981.

Glick, I. Foctors of community well-being as identified by residents of a resotarce town, (Ph.D. Thesis). Edmonton: U. of Alberta, 1983.

Goodman, E. Regular Column, The Washington Past. Date not known.

Kuha, T. The structure of scientific revolutions. Chicago: Phoenix Books Edition, U. of Chicago Press, 1970.
Polak, F. The image of the furure. New York: Elsevief Scientific Publishing Co., 1973.

Seligman, M. Helplessness: On depression, development and death. San Francisco: W.H. Freeman, 1975.

Watzlawick, P., Weakland, C., \& Fisch, R. Change: Principles of problem formation and problem resotution. New York: W. W. Norton \& Co 1974.

Zautra, A., \& Simons, 1. Some effects of positive life events on community mental bealth. In Zautra \& Goodhart, Community Mental Heshh Review, Vol. 4, No, 1, Spring, 1979. 